Received Date : 28-Mar-2016

Revised Date : 13-Dec-2016

Accepted Date : 21-Dec-2016

Article type : Original Article

\title{
Electrochemotherapy in the treatment of metastatic malignant melanoma: A prospective cohort study by InspECT
}

C. Kunte ${ }^{1}$, V. Letulé ${ }^{1}$, J. Gehl ${ }^{2}$, K. Dahlstroem ${ }^{3}$, P. Curatolo ${ }^{4}$, R. Rotunno ${ }^{4}$, T. Muir $^{5}$, A. Occhini ${ }^{6}$, G. Bertino ${ }^{6}$, B. Powell ${ }^{7}$, W. Saxinger ${ }^{8}$, G. Lechner ${ }^{8}$, S.-H. Liew ${ }^{9}$, R. Pritchard-Jones ${ }^{9}$, P. Rutkowski ${ }^{10}$, M. Zdzienicki ${ }^{10}$, D. Mowatt ${ }^{11}$, A. J. Sykes ${ }^{12}$, A. Orlando ${ }^{13}$, G. Mitsala ${ }^{13}$, C. R. Rossi ${ }^{14,15}$, L. Campana ${ }^{14,15}$, M. Brizio ${ }^{16}$, F. de Terlizzi $^{17}$, P. Quaglino ${ }^{16+}$, J. Odili $^{7+}$

+both authors equally contributed to this study

${ }^{1}$ Department of Dermatology and Allergology, Ludwig-Maximilian University Munich, Germany

${ }^{2}$ Center for Experimental Drug and Gene Electrotransfer, Department of Oncology, Copenhagen University Hospital Herlev, Herlev, Denmark

${ }^{3}$ Department of Plastic Surgery, Copenhagen University Hospital Herlev, Denmark ${ }^{4}$ Department of Dermatology and Plastic Surgery, Dermatologic Clinic, University of Rome "La Sapienza", Rome, Italy

${ }^{5}$ Department of Reconstructive Plastic Surgery, James Cook University Hospital, Middlesbrough, UK

${ }^{6}$ Department of Otolaryngology Head \& Neck Surgery, University of Pavia, IRCCS Policlinico San Matteo Foundation, Pavia, Italy

${ }^{7}$ Department of Plastic Surgery, St. Georges Hospital, London, United Kingdom ${ }^{8}$ Department of Dermatology, Klinikum Wels-Grieskirchen, Wels, Austria ${ }^{9}$ Department of Plastic Surgery, Whiston Hospital, Prescot, Merseyside, United Kingdom

${ }^{10}$ Department of Soft Tissue/Bone Sarcoma and Melanoma, Maria Sklodowska-Curie Memorial Cancer Center and Institute of Oncology, Warsaw, Poland

${ }^{11}$ Plastic Surgery Department, Christie Hospital, NHS Foundation Trust, Manchester, United Kingdom

${ }^{12}$ Department of Clinical Oncology, Christie Hospital, NHS Foundation Trust, Manchester, United Kingdom

This article has been accepted for publication and undergone full peer review but has not been through the copyediting, typesetting, pagination and proofreading process, which may lead to differences between this version and the Version of Record. Please cite this article as doi: $10.1111 /$ bjd. 15340

This article is protected by copyright. All rights reserved. 
${ }^{13}$ Department of Plastic and Reconstructive Surgery, Southmead Hospital, North Bristol NHS Trust, Bristol, United Kingdom

${ }^{14}$ Veneto Institute of Oncology IOV-IRCCS, Padova, Italy

${ }^{15}$ Department of Surgery Oncology and Gastroenterology, University of Padova, Padova, Italy

${ }^{16}$ Department of Medical Sciences, Dermatologic Clinic, University of Torino, Italy ${ }^{17}$ Scientific \& Medical Department, IGEA S.p.A.

InspECT (International Network for Sharing Practice on Electrochemotherapy)

\section{Corresponding Author:}

Christian Kunte, MD,

Department for Dermatology and Allergy

University Hospital of Munich (LMU)

Frauenlobstr. 9-11

80337 Munich

Germany

christian.kunte@med.uni-muenchen.de

\section{Abstract}

Background: Electrochemotherapy (ECT) is an effective local treatment for cutaneous metastasis. Treatment involves the administration of chemotherapeutic drugs followed by delivery of electrical pulses to the tumour. The aim of this study was to investigate the effectiveness of ECT in cutaneous metastases of melanoma and to identify factors which affect (beneficially or adversely) the outcome.

Methods: 13 cancer centres in the International Network for Sharing Practices on Electrochemotherapy (INSPECT) consecutively and prospectively uploaded data to a common database. ECT consisted of intratumoural or intravenous injection of bleomycin, followed by application of electric pulses under local or general anaesthesia.

Results: 151 patients with metastatic melanoma were identified from the database, 114 of which had follow-up data of 60 days or more. 80 of these patients $(73 \%)$ experienced an overall response (complete response + partial response = OR). 394 lesions were treated, of which 306 (77\%) revealed an OR, 229 a complete response (58\%). In multivariate analysis, factors positively associated with overall response were coverage of deep margins, absence of visceral metastases, presence of 
lymphoedema, treatment of non-irradiated areas were factors significantly influencing treatment efficacy. Factors significant associated to a complete response to ECT treatment were: coverage of deep margins, previous irradiation of treated area, and tumour size $(<3 \mathrm{~cm})$. One-year overall survival in this cohort of patients was $67 \%$ (C.I. $95 \%$ : $57 \%-77 \%$ ), whilst melanoma specific survival was $74 \%$ (C.I. $95 \%: 64 \%-84 \%)$. No serious adverse events were reported, and the treatment was in general very well tolerated.

Conclusion: ECT is a highly effective local treatment for melanoma metastases in the skin, with no severe adverse effects. In the presence of certain clinical factors, ECT may be considered for local tumour control as an alternative to established local treatments, or as an adjunct to systemic treatments. .

Keywords: Electrochemotherapy, malignant melanoma, palliative care, bleomycin.

\section{Bulleted summary}

\section{What's already known about this topic?}

Electrochemotherapy (ECT) is an effective local treatment for cutaneous metastasis. Treatment efficacy is correlated to tumour size.

\section{What does this study add?}

With multivariate analysis, several new factors associated with a favourable response to treatment have been identified: coverage of deep tumour margin, presence of lymphoedema, treatment of non-irradiated areas, and absence of visceral metastases.

\section{Introduction}

Therapy and management of metastatic melanoma is challenging. Melanoma accounts for about $18 \%$ of the total cases of cutaneous metastases ${ }^{1,2}$. Patients with metastatic disease may suffer reduced quality of life because of pain, discharge, bleeding, and malodour of the tumours. In this advanced stage of disease, a multimodal palliative treatment, focusing on alleviating symptoms for the patients, is 
required. Established therapeutic options include surgery, immunotherapy, systemic chemotherapy, isolated limb perfusion, radiotherapy, laser ablation and radiofrequency ablation, depending on the location of metastases and the condition of the patient ${ }^{3,4}$.

Electrochemotherapy (ECT) is a well-established treatment option for cutaneous and subcutaneous metastases, including melanoma ${ }^{5}$. Originally, it was used for the treatment of metastatic head and neck cancer ${ }^{6}$ and has since been established in the treatment of tumours of different histological types. Moreover, it has a favourable risk-to-benefit profile due to its simplicity, cost-effectiveness, safety and limited toxicity ${ }^{7}$.

Electroporation is a physical delivery system to enhance the penetration of different types of molecules, e.g. drugs ${ }^{6}$. The use of short electrical local pulses via an electrode leads to destabilisation of the cell membrane and transiently increases the permeability of the tumour cell membrane, thus enabling diffusion of the agents. This potentiates the cytotoxicity of the non-permeant or poorly-permeant anticancer drug 6,8 . The secondary actions of ECT include a reduction of tumour blood flow and a localised vascular disruption resulting in increased effectiveness of the drug ${ }^{9-11}$. Bleomycin and cisplatin have been identified as the most suitable and effective drugs for ECT and can be used intratumourally or intravenously ${ }^{12}$. The cytotoxic effect of Bleomycin is potentiated approximately 8000 times, and that of Cisplatin 80 times $^{13}$.

Several studies have investigated the effectiveness of ECT ${ }^{2,13-30}$. A study on the efficacy and safety of ECT published in 2006 by Mir et al. established the European standard operating procedures (ESOPE) ${ }^{23}$. Kis et al. compared their outcomes of ECT in patients with melanoma with the results of the ESOPE study ${ }^{13}$. A recent systematic review has compared different studies on therapies for cutaneous tumours regarding overall effectiveness ${ }^{31}$.

ECT has been recognized by a number of national health services, including the National Institute for Health and Care Excellence (NICE) as an integral part of the multidisciplinary treatment options for patients with skin metastases of non-skin origin and melanoma ${ }^{5}$. 
ECT has been reported to be highly effective in the treatment of cutaneous and subcutaneous metastases. Objective response rates range from 75-99\% 8,13,23,31. The high response rates found consistently across studies reflect a dramatic increase of the cytotoxic effect of the cytostatic drugs, such as bleomycin, when access into the cell cytosol is facilitated by permeabilization of the plasma membrane. In order for the therapy to work efficiently it is important that sufficient drug dose is present, and that the tumour volume is covered by the electric pulses 21,23

The aim of this study was to review the effectiveness of ECT in cutaneous metastases of melanoma and to identify factors which affect (beneficially or adversely) the outcome. Local progression free and overall survival were further aims of the study. The results may be used prospectively to further improve the effectiveness of ECT in metastatic melanoma. This study focussed on the response of ECT to local disease in the skin, and did not compare response rates with other treatment modalities for metastatic disease.

\section{Methods}

\section{Patients}

Patients were treated consecutively at 13 institutions in the INSPECT network (Bristol, Copenhagen, London, Manchester, Middlesbrough, Munich, Padova, Pavia, Prescot Merceyside, Rome, Turin, Warsaw, Wels). Patients were consented, then data entered onto the database and subsequently updated over time. All centres uploaded data prospectively. No patient subsequently asked for their data to be removed from the database. Accrual time was from July 2007 to September 2014. Approval from ethics committee, and data protection authority was sought by each institution. Clinical information retrieved from the database included: demographics; type of tumour; number of treated lesions, site and size of the largest lesion, previous irradiation, duration of follow-up, and possible retreatment with ECT at subsequent time point. Patients treated had histologically malignant melanoma with measurable cutaneous metastases, or mucosal lesions, suitable for application of electric pulses. Patients had been offered standard treatment options, were $\geq 18$ years old, had Eastern Cooperative Oncology Group (ECOG) performance status $\leq 2$, a life expectancy of at least three months, and, if fertile were using adequate 
contraception. Patients were not treated if they previously had allergic reactions to bleomycin or to any of the components required for anaesthesia, if the cumulative dose of $250 \mathrm{mg}$ bleomycin/m2 (400.000 IU bleomycin/m2) had previously been exceeded, had chronic renal dysfunction (serum creatinine $>150 \mu \mathrm{mol} / \mathrm{l}$ ) or acute lung infection. Metastases were targeted for ECT regardless of pigmentation.

\section{Procedure}

ECT was performed according to the ESOPE Standard Operating Procedures ${ }^{23}$. Briefly, bleomycin was administrated either intratumourally (i.t.) using $1000 \mathrm{IU} / \mathrm{ml}$ or intravenously (i.v) using $15.000 \mathrm{IU} / \mathrm{m}^{2}$, intratumoural or intravenous dosage was chosen depending on the number of cutaneous metastases to be treated and size of metastases. Depending on clinician's choice, one of the following electrodes was used: 1) Type I electrodes: two plates with a $6 \mathrm{~mm}$ gap between the plates; 2) Type II electrodes: two parallel rows of needles with $4 \mathrm{~mm}$ between rows; 3) Type III electrodes: a hexagonal array with $7.9 \mathrm{~mm}$ between the needles. Electric pulses (eight pulses of $100 \mu$ s duration) were delivered using a square wave electroporator (IGEA, Carpi, Italy). After ECT, the treated metastases were covered with standard dressings where necessary.

Coverage of deep and lateral margins were not pre-specified, but was at the treating physician's discretion, and the database offered a possibility for the physician to indicate whether these respective margins were completely covered/ treated or not. Targeting deep margin was assessed either clinically by palpating subcutaneous infiltration or fixation to the depth, or by using ultrasound.

\section{Response evaluation}

Locoregional tumour response was evaluated according to the Response Evaluation Criteria in Solid Tumours (RECIST version 1.0), modified to only include response of the treated cutaneous metastases. Complete response (CR) was defined as disappearance of the target lesion; partial response (PR) with at least 30\% decrease in the diameter of the target lesion. Progressive disease (PD) was defined as at least $20 \%$ increase in the diameter of the target lesion and stable disease (SD) with neither sufficient shrinkage to qualify for PR or sufficient increase to qualify for PD. A maximum of seven cutaneous metastases per patient (including the largest tumour) were registered as target lesions, as in previous studies ${ }^{2,21}$. The longest diameter of 
the tumours was measured and recorded and photographs taken at the time of treatment, and at subsequent follow-up visits.

\section{Pre-operative evaluation}

Selection of the target nodule was performed according to the RECIST criteria (version 1.1). Pain intensity was evaluated using the Numeric Rating Scale (NRS) for pain. NRS is a unidimensional 11-point numeric scale between ' 0 ' as 'no pain' and '10' as 'worst pain'. We used a previously published cut-off on NRS score: 0-2 mild pain, 3-4 moderate pain, and 5-10 severe pain. Pain medication was registered as 'none', 'sometimes', 'controlled by non-opioids', 'controlled by opioids', 'uncontrolled', or 'unknown'. Evaluation of pain and pain medication was repeated at follow-up visit 32.

\section{Statistics}

Continuous variables were described by median value and interquartile range, categorical variables by absolute number and percentage. Analysis of response for different lesions' sizes have been reported on 2 by k contingency table and analysed with Chi Square test for trend. Chi Square value (and degree of freedom) have been reported together with $p$ value. Several groups have been compared on the basis of clinical and treatment variables (sex, age </>70yrs, time since diagnosis $</>5 y r s, T$ stage at timepoint of diagnosis (T1-T2 vs T3-T4), localisation (limbs vs other), number of treated lesions $</>3$, size of lesions $</>3 \mathrm{~cm}$, presence of visceral metastases, treatment of pre-irradiated areas, presence of lymphoedema, complete treatment of deep margins, complete treatment of lateral margins, previous treatments (surgery, chemotherapy, radiotherapy, isolated limb perfusion (ILP), other treatments), number of ECT treatments (1 vs multiple), current ( $\leq 2$ Ampère, $>2$ Ampère), electrodes (hexagonal vs other)). Multivariable analysis was performed by logistic regression model using objective response (yes/no) and then complete response only (yes/no), using as covariates only significant variables observed in the univariable analysis. Local tumour control was expressed as local progression free survival which was the time from ECT up to the date to relapse or progression or last follow-up, (whichever came first). Overall survival was calculated from the first ECT up to death or last follow-up. Survival curves were calculated by the Kaplan-Meier 
method. $p<0.05$ was considered statistically significant. One-year survival and 95\% confidence interval (C.I. 95\%) were calculated using Kaplan-Meier survival analysis. Overall survival was calculated at death (for any reason) of patient or last follow-up, melanoma specific survival was calculated at death of patient for melanoma disease or last follow-up. Statistical analyses were performed with NCSS 9 software (NCSS, LLC. Kaysville, Utah, USA)

\section{Results}

\section{Patients}

A total of 151 patients were treated by ECT and uploaded to the INSPECT database by 13 European centres (Bristol $(n=4)$, Copenhagen $(n=14)$, London $(n=29)$, Manchester $(n=10)$, Middlesbrough $(n=14)$, Munich $(n=19)$, Padova $(n=7)$, Pavia $(n=3)$, Prescot Merceyside $(n=9)$, Rome $(n=8)$, Turin $(n=27)$, Warsaw $(n=2)$, Wels $(\mathrm{n}=5))$.

Of these patients, 37 did not have a minimum follow-up time of 60 days (a requisite to evaluate the response to treatment by RECIST criteria). These patients were therefore excluded from the study (death not directly related to treatment $(\mathrm{N}=12 ; 8$ of them died due to systemic disease progression, 4 of other causes unrelated to melanoma or ECT treatment), use of other treatments non-specified $(\mathrm{N}=6)$, systemic disease progression $(N=6)$, inability to reach the hospital for follow-up visits $(N=1)$, lost to follow-up $(\mathrm{N}=12)$ ).

Therefore, of 151 patients identified from the database, 114 patients have been evaluated for tumour response. Population and tumour characteristics of the entire cohort of 151 patients (506 treated lesions) and of the 114 patients (394 treated lesions) evaluable for response are reported in table 1.

\section{Anaesthesia}

Local or general anesthesia was selected according to the tumour burden and location as well as to patient's choice, following the SOP (Standard Operating Procedures). General anaesthesia was used in the majority of cases (95 patients, $63 \%)$. In 36 patients ECT was performed under local anesthesia and deep sedation (24\%). The remaining 20 patients were treated with local anesthesia alone (13\%). A similar percentage distribution was observed in the 114 patients group (62\%, 26\% and $12 \%$ respectively). 


\section{Electrochemotherapy}

123 patients received a single ECT session (82\%), 21 patients (14\%) were treated twice, 5 patients (3\%) with three, 2 patients (1\%) with 4 ECT sessions. Bleomycin was administered by systemic injection in 131 patients (87\%) and by local injection in 20 patients (13\%). Electrodes used were: hexagonal in $383(76 \%)$, row needle in 67 (13\%), plate in 20 (4\%), multiple electrodes were used in 36 lesions (7\%). Of the 506 treated target lesions, $37(7 \%)$ were previously irradiated. Deep margins were treated by ECT in 363 lesions (72\%), lateral margins were reached in 385 lesions (76\%). Similar percentage distributions were observed in the subgroup of 114 patients and 394 target lesions evaluable for response (Table 1).

\section{Treatment toxicity}

No ECT-related serious adverse events were reported. Skin reaction (including hyperpigmentation and ulceration) after treatment was observed in 63 patients (42\%) of which in 2 patients of grade G3. Fifteen patients experienced post-treatment complications: nausea (G1-G2) in 5 patients (3\%), flu-like symptoms (G1-G2) in 6 patients (4\%), lymphoedema (G1-G2) in 4 patients (3\%). A similar percentage distribution was observed in the 114 patients group (skin reaction 50\% 2 of grade G3, nausea $4 \%$, flu 5\%, lymphoedema 4\%). Post-treatment pain was observed in 59 patients (39\%), were mild in the majority of patients and could be managed with oral analgesics. No significant changes in pain and pain medication in the course of the treatment could be observed (Table 2).

\section{Locoregional tumour response}

394 target lesions could be evaluated for response at $>60$ days follow-up. Median size was $9 \mathrm{~mm}$ (I.Q. range 5-20 mm). At 60 days from ECT, 229 lesions showed a complete response (58\%), 77 showed a partial response (19\%) (Overall response 306 of 394 lesions $=77 \%), 79$ lesions remained stable $(20 \%), 6$ had disease progression (2\%) and 3 were not evaluable (1\%) due to the presence of thick crusts. Of the 114 evaluable patients, at >60 days follow-up 55 had a complete response (48\%), 29 a partial response (25\%) (Overall response 80/114 patients - $73 \%$ ), 26 patients were in stable disease (23\%), 3 patients had disease progression (3\%) and 1 patient was not evaluable due to the presence of thick crusts. We found a significant trend between tumour size and complete response to ECT $(p<0.0001$, Table 3). 


\section{Predictive factors for response}

Among all clinical and technical covariates included in the univariate analysis, those significantly associated to response to treatment were: tumour size $(<3 \mathrm{~cm})$, absence of visceral metastases, treatment of non-irradiated areas, presence of lymphoedema, coverage of deep margins and lateral margins (Table 4).

Looking at overall response (complete response + partial response $=\mathrm{OR}$ ) in multivariate analysis, coverage of deep margins, absence of visceral metastases, presence of lymphoedema, treatment of non-irradiated areas were factors significantly influencing treatment efficacy. In multivariate analysis significant factors associated to a complete response to ECT treatment were: coverage of deep margins, previous irradiation of treated area, and tumour size $(<3 \mathrm{~cm})($ Table 5).

\section{Local tumour control and survival}

Median follow-up time was 116 days [I.Q. range 66-201 days]. Local tumour control survival curve is shown in figure 1. Twenty-seven patients had been followed up for at least 200 days and at this time local tumour control survival rate was $86 \%$.

The 51 patients in complete response at 2 months of follow-up were locally disease free for a median time of 125 days [I.Q. range 70-209 days]. Eight of them had a second ECT for new lesions after a median time of 96 days [I.Q. range 61-154 days]. Five patients were treated for new lesions outside the treated area. Three patients were retreated for recurrences in the treated area, two of them had a total of 4 ECT sessions and maintained local tumour control for 374 and 447 days respectively.

Overall, the 8 patients experienced median local tumour control survival of 254 days [I.Q. range 161-389 days].

Among the 29 patients with a partial response, 10 were re-treated by ECT after a median time period of 90 days [I.Q. range 58-131 days], and resulted in 2 complete responses, 4 partial responses, 1 stable disease, 1 progressive disease and 2 were not evaluable. For the 6 patients with $\mathrm{CR} / \mathrm{PR}$, local control of the disease was maintained for a median follow-up time of 125 days [I.Q. range 99-262 days].

Overall $27(23.7 \%)$ patients were re-treated with ECT after a median follow-up time of 91 days [I.Q. range 61-133 days], and in these patients, local tumour control was maintained for a median time of 178 days since the first ECT session [I.Q. range 106-277 days]. 
One-year overall survival in this cohort of patients was 67\% (C.I. 95\%: 57\%-77\%), whilst melanoma specific survival was 74\% (C.I. 95\%: 64\%-84\%).

\section{Discussion}

The incidence of melanoma has been rising over a number of years and is currently the most common malignancy in young adults (American Cancer Society, 2015). Some of these patients will go on to develop metastases giving rise to pain, ulceration, malodor and bleeding. These patients have an immeasurable psychological burden and their quality of life can be adversely affected. The five-year survival for patients with in-transit disease has up to now ranged from $12-37 \%{ }^{33}$, although this will hopefully improve with novel treatment regimens ${ }^{34,35}$.

ECT is an established therapeutic approach for the local treatment of skin metastases regardless of tumour histology ${ }^{21,23}$. In a recent meta-analysis on more than 40 prospective studies comparing five skin-directed therapies (ECT, radiation, photodynamic therapy, intralesional therapy, and topical therapy), ECT demonstrated an OR rate of $75.4 \%$ (CR rate, $47.5 \%$ ) with a low toxicity profile (grade 3 in less than $6 \%$ of patients). In this analysis, melanoma comprised $83.3 \%$ of all cutaneous metastases ${ }^{31}$. Another previously published meta-analysis of ECT for cutaneous and/or subcutaneous malignancy (including primary nonmetastatic disease) reported a CR rate of $59 \%^{8}$.

Our data retrieved from this multicentre observational prospective study which included the largest cohort of patients treated by ECT reported, strongly confirm the results of previous studies, highlighting the clinical activity of ECT in terms of response rate and response duration ${ }^{13,15-18,24-27,30,36}$. Indeed, at 2-month follow-up, a response was achieved in $77 \%$ of target lesions (58\% CR rate) and in $73 \%$ of patients (48\% achieving a CR). Notably, the local tumour control was $86 \%$ at 200 days of follow-up, meaning that patients with CR maintained their response for a prolonged period of time.

These results correspond to those reported by studies analysing long term followup. Caracò et al. reported that $44.8 \%$ of complete responders experienced a longlasting response after one ECT session and were disease-free after a mean duration 
of follow-up of 27.5 months ${ }^{18}$. In our study as well as in former published studies, the clinical activity of ECT was accompanied with a favourable toxicity profile with no severe side effects. Concerns regarding post treatment pain have been addressed 32,37 with the majority of patients reported as experiencing no pain or mild pain. Patients deemed at a higher risk of post-procedure pain can be identified preoperatively, and cope well with an established pain management strategy. The results from this paper showed $39 \%$ of the patients suffered from post treatment pain, managed by oral analgesia alone. This is similar to that previously published 32,37. No other severe adverse effects were noted.

Whilst the clinical indications and tolerability of ECT is widely accepted, a still controversial issue is the identification of patients most likely to develop and maintain response to ECT. This is particularly important since new and active systemic drugs for metastatic melanoma (both immune therapies such as anti-CTLA4 or antiPD1/PD1L inhibitors and anti-BRAF/MEK target inhibitors) are available that may also be used in the same population of patients. The aim of this study was to identify parameters significantly influencing treatment response and helping to decide whether a patient is more suitable for systemic therapy or ECT. To date, there is no consensus in the literature as to how best identify these factors. The only parameter which the large majority of publications agree on is the size of lesions ${ }^{38}$.

It is well known that smaller tumours respond better, likely both due to faster healing (time to clinical response), due to a more aggressive phenotype in larger tumours, and possibly also due to technical limitations when treating very large tumours ${ }^{2,15,24}$. We found a significant and inverse trend between tumour size and treatment response. Treatment efficiency decreased with increasing size of tumour nodules (Table 3).

However only a few studies have tried to identify other factors influencing treatment response. Solari et al. found that response rate significantly correlated at univariate analysis both with the number (< or $>10)$ and the size $(<$ or $>2 \mathrm{~cm}$ ) of metastases, whilst in multivariate analysis only the tumour size maintained a statistically significant correlation in 39 patients ${ }^{27}$. However, this study was conducted on a relatively small cohort including not only melanoma but also other tumours. Campana et al. identified in their study on 85 metastatic melanoma patients tumour 
size and number of lesions, as significant predictive factors for response in multivariate analysis ${ }^{17}$. Increasing number of electrode applications and ECT cycles were reported as predictors of local tumour control and the location of nodules on the lower limb was associated with improved survival ${ }^{17}$.

In the present study, we identified the following predictors of response: coverage of deep tumour margins, absence of visceral metastases, presence of lymphoedema and treatment of non-irradiated areas. Our analysis identified factors not previously reported in melanoma patients. The size of the lesion, which is a well-known prognostic parameter in ECT treated patients $(<3 \mathrm{~cm}$ in diameter) was singled out by the multivariate model only in relation to a significantly higher probability of achieving a complete response to treatment. This factor was not associated with a better overall response. On the other hand, complete coverage of deep margins and treatment of tumours in non-irradiated areas were significant parameters on multivariate analysis on overall and complete response. The relevance of completely targeting the deep margins could imply that patients with deep and/or subcutaneous metastases could have a lower response rate to ECT in contrast to patients with superficial skin lesions, although the assessment of deep margins still needs to be assessed in a more reproducible way.

The number of tumours was not found to be a predictor of locoregional tumour response in our patients.

The biological background leading to a reduced ECT activity in the presence of these parameters can be hypothesized even if not specifically addressed in this paper. The presence of visceral metastases could be considered as a putative biomarker of rapid cell growth and therefore aggressive metastatic behaviour. In these cases, one could infer that the local approach by ECT alone would be inadequate to manage local disease occurrence or the onset of new skin lesions. In addition, there is a higher tumour load in patients with systemic metastases, and a retrograde metastasis from viscera to the skin is possible. This could occur if lymph node metastasis results in a blockage of lymph flow, incompetent lymphatic valves, and subsequent retrograde lymphatic flow. (Grinnell 1966) 
Intriguingly, the presence of lymphoedema was associated with a higher response to ECT. Lymphoedema is a common surgical side effect of radical node dissection and therefore patients with skin "in-transit metastases" often present with this picture.

Data is emerging that ECT may be an efficient way of presenting intact antigens to the immune system, as electroporation is essentially a non-thermal therapy ${ }^{39}$. Case reports of excellent responses after sequential ECT and immunotherapy are accumulating, and a study has found homing of T-lymphocytes to tumour lesions after ECT of other lesions, in combination with local IL- $2^{34}$. What can be speculated, but must be further investigated, is that an increased presence of lymphocytes in the treated area may have a positive effect on response. Such a response may not be seen e.g. in isolated limb perfusion because the drugs used will also be cytotoxic to lymphocytes.

Radiotherapy is not a standard treatment for primary melanoma, but can be used to treat metastatic lesions. The observation of better ECT response in non-irradiated lesions (when compared to lesions in patients with previous irradiation) could be explained by reduced clinical tumour activity due to the modification in the tumour microenvironment and vascularisation induced by radiotherapy. Fibrosis is a late side-effect of radiation caused by premature senescence and accelerated postmitotic differentiation, leading to excessive collagen production by irradiated mesenchymal cells (fibroblasts, myofibroblasts, and smooth muscle cells), and not by cell kill ${ }^{40,41}$. The presence of fibrosis may alter the electric potential delivered during ECT treatment. Conversely there is laboratory evidence that ECT performed before radiotherapy ${ }^{42}$ or in combination with irradiation ${ }^{43}$, might give rise to good anti-tumour results. It is thought the anti-tumour effectiveness of ECT is increased by radiation in the laboratory model. Other studies have shown that ECT acts synergistically with radiotherapy, with enhanced tumour toxicity ${ }^{42-44}$. Possibly, in melanoma, restricted blood flow and fibrosis may also lead to decreased immunological activity in the area.

It is important to determine the various factors which will positively affect the outcome of melanoma patients treated with ECT. Our data suggest that patients with skin metastases, could be selected for ECT treatment if the disease was superficial, in the presence of lymphoedema, in the absence of visceral metastases or previous 
irradiation, and if the tumour nodules were less than $3 \mathrm{~cm}$ dimension. It may even be possible that ECT could favourably influence immunotherapeutic approaches, and studies are ongoing to investigate this. Patients with visceral metastases, absence of lymphoedema, larger and deep skin metastases and with previous radiotherapy could be treated earlier with a systemic approach and ECT performed only if needed to control bleeding of metastases.

There are a number of limitations to the current study. Patient review is not standardised in all the Centres involved in the data collection. In some units, ECT is carried out by specific personnel and therefore assessment of response is likely to be biased. The number of patients assessed for the cohort study does not accurately represent the total number of melanoma patients treated. The various centres joined InspECT at different times and the ability to upload data was related to local resources and the availability of personnel. The ability to determine whether or not the deep margin of a tumour is treated remains subjective, by the treating clinician. One way to objectively characterise the deep treatment margins would be intraoperative imaging by ultrasound.

Future studies on ECT could explore the use of ECT as monotherapy for localised skin metastases, only adding systemic treatments when there is systemic progression to prevent early resistance to systemic treatments and to achieve long lasting survival rates. It is already well established, that ECT does not influence the metastatic potential of tumour cells ${ }^{45}$. If it is not possible to treat deep tumour margins it may be necessary to add a systemic treatment early due to worse response rates (10.28 for $\mathrm{CR}$ and 28.45 for $\mathrm{OR}$ ).

ECT is a once-only treatment, and can be quickly performed, even before or between other treatments. Clear indications include bleeding ${ }^{10,19}$, which is a frequent problem for patients afflicted with metastatic melanoma. Local responses, which are to a high degree achievable with ECT, may alleviate the patient from local tumour burden and progression.

The collection of InspECT data began before the introduction of targeted therapies, like BRAF, ckit, MEK1 and NRAS mutations, and so this status has not been systematically evaluated in our patients. Future studies could ascertain whether ECT 
activity could be influenced by the mutation status or are independent from it.

Ultimately a randomised controlled trial will determine whether there is a difference in locoregional response rate and overall survival when ECT is compared to other well established treatment modalities. Future studies to explore the combination of ECT with systemic treatments will become necessary with time as more of our patients become eligible for treatment with new agents. ${ }^{30}$. The combination of ECT with immunotherapy or targeted therapies could be a strategy to target both local and distant unreachable or untreated lesions ${ }^{25}$.

\section{Conflict of interest statement}

Igea (Carpi, Italy) hosts the INSPECT database, but the database is controlled by an independent board, and the uploaded data are contractually belonging to the investigators involved. Francesca de Terlizzi is an IGEA employee.

Christian Kunte and Joy Odili received honoraria for lectures and were invited to meetings on Electrochemotherapy by IGEA

\section{Literature}

1 Lookingbill DP, Spangler N, Helm KF. Cutaneous metastases in patients with metastatic carcinoma: a retrospective study of 4020 patients. J Am Acad Dermatol 1993; 29: 228-36.

2 Matthiessen LW, Chalmers RL, Sainsbury DC et al. Management of cutaneous metastases using electrochemotherapy. Acta Oncol 2011; 50: 621-9.

3 Kahler KC, Egberts F, Gutzmer R. Palliative treatment of skin metastases in dermatooncology. J Dtsch Dermatol Ges 2013; 11: 1041-5; quiz 6.

4 Testori A, Rutkowski P, Marsden J et al. Surgery and radiotherapy in the treatment of cutaneous melanoma. Ann Oncol 2009; 20 Suppl 6: vi22-9.

5 NICE. Electrochemotherapy for metastases in the skin from tumours of non-skin origin and melanoma. In. 4. 2013; NIfHaCE.

6 Belehradek M, Domenge C, Luboinski B et al. Electrochemotherapy, a new antitumor treatment. First clinical phase I-II trial. Cancer 1993; 72: 3694-700.

7 Reinhold U. [Electrochemotherapy of skin tumors]. Hautarzt 2011; 62: 549-58; quiz 59.

8 Mali B, Jarm T, Snoj M et al. Antitumor effectiveness of electrochemotherapy: a systematic review and meta-analysis. Eur J Surg Oncol 2013; 39: 4-16.

9 Gehl J, Skovsgaard T, Mir LM. Vascular reactions to in vivo electroporation: characterization and consequences for drug and gene delivery. Biochim Biophys Acta 2002; 1569: 51-8.

10 Markelc B, Sersa G, Cemazar M. Differential mechanisms associated with vascular disrupting action of electrochemotherapy: intravital microscopy on the level of single

This article is protected by copyright. All rights reserved. 
normal and tumor blood vessels. PLoS One 2013; 8: e59557.

11 Sersa G, Cemazar M, Miklavcic D et al. Tumor blood flow modifying effect of electrochemotherapy with bleomycin. Anticancer Res 1999; 19: 4017-22.

12 Sersa G, Cemazar M, Snoj M. Electrochemotherapy of tumours. Curr Oncol 2009; 16: $34-5$.

13 Kis E, Olah J, Ocsai H et al. Electrochemotherapy of cutaneous metastases of melanoma--a case series study and systematic review of the evidence. Dermatol Surg 2011; 37: 816-24.

14 Brizio M, Fava P, Astrua C et al. Complete regression of melanoma skin metastases after electrochemotherapy plus ipilimumab treatment: an unusual clinical presentation. Eur J Dermatol 2015; 25: 271-2.

15 Campana LG, Mocellin S, Basso M et al. Bleomycin-based electrochemotherapy: clinical outcome from a single institution's experience with 52 patients. Ann Surg Oncol 2009; 16: 191-9.

16 Campana LG, Testori A, Mozzillo N et al. Treatment of metastatic melanoma with electrochemotherapy. J Surg Oncol 2014; 109: 301-7.

17 Campana LG, Valpione S, Mocellin S et al. Electrochemotherapy for disseminated superficial metastases from malignant melanoma. Br J Surg 2012; 99: 821-30.

18 Caraco C, Mozzillo N, Marone U et al. Long-lasting response to electrochemotherapy in melanoma patients with cutaneous metastasis. BMC Cancer 2013; 13: 564.

19 Gehl J, Geertsen PF. Efficient palliation of haemorrhaging malignant melanoma skin metastases by electrochemotherapy. Melanoma Res 2000; 10: 585-9.

20 Heller R, Jaroszeski MJ, Reintgen DS et al. Treatment of cutaneous and subcutaneous tumors with electrochemotherapy using intralesional bleomycin. Cancer 1998; 83: 148-57.

21 Marty M, Sersa G, Garbay JR et al. Electrochemotherapy - An easy, highly effective and safe treatment of cutaneous and subcutaneous metastases: Results of ESOPE (European Standard Operating Procedures of Electrochemotherapy) study. Eur J Cancer Supplements 2006; 4: 3-13.

22 Matthiessen LW, Johannesen HH, Hendel HW et al. Electrochemotherapy for large cutaneous recurrence of breast cancer: a phase II clinical trial. Acta Oncol 2012; 51: 713-21.

23 Mir LM, Gehl J, Sersa G et al. Standard operating procedures of the electrochemotherapy: instructions for the use of bleomycin or cisplatin administered either systemically or locally and electric pulses by the Cliniporator TM by means of invasive or non-invasive electrodes. Eur J Cancer Supplements 2006; 4: 14-25.

24 Quaglino P, Mortera C, Osella-Abate S et al. Electrochemotherapy with intravenous bleomycin in the local treatment of skin melanoma metastases. Ann Surg Oncol 2008; 15: 2215-22.

25 Queirolo P, Marincola F, Spagnolo F. Electrochemotherapy for the management of melanoma skin metastasis: a review of the literature and possible combinations with immunotherapy. Arch Dermatol Res 2014; 306: 521-6.

26 Snoj M, Cemazar M, Srnovrsnik T et al. Limb sparing treatment of bleeding melanoma recurrence by electrochemotherapy. Tumori 2009; 95: 398-402.

27 Solari N, Spagnolo F, Ponte E et al. Electrochemotherapy for the management of cutaneous and subcutaneous metastasis: a series of 39 patients treated with palliative intent. J Surg Oncol 2014; 109: 270-4.

28 Tijink BM, De Bree R, Van Dongen GA et al. How we do it: Chemo-electroporation in the head and neck for otherwise untreatable patients. Clin Otolaryngol 2006; 31: 447-51.

This article is protected by copyright. All rights reserved. 
29 Tozon N, Pavlin D, Sersa G et al. Electrochemotherapy with intravenous bleomycin injection: an observational study in superficial squamous cell carcinoma in cats. $J$ Feline Med Surg 2014; 16: 291-9.

30 Valpione S, Campana LG, Pigozzo J et al. Consolidation electrochemotherapy with bleomycin in metastatic melanoma during treatment with dabrafenib. Radiol Oncol 2015; 49: 71-4.

31 Spratt DE, Gordon Spratt EA, Wu S et al. Efficacy of skin-directed therapy for cutaneous metastases from advanced cancer: a meta-analysis. J Clin Oncol 2014; 32: 3144-55.

32 Quaglino P, Matthiessen LW, Curatolo P et al. Predicting patients at risk for pain associated with electrochemotherapy. Acta Oncol 2015; 54: 298-306.

33 Pawlik TM, Ross MI, Thompson JF et al. The risk of in-transit melanoma metastasis depends on tumor biology and not the surgical approach to regional lymph nodes. $J$ Clin Oncol 2005; 23: 4588-90.

34 Andersen MH, Gehl J, Reker S et al. Dynamic changes of specific T cell responses to melanoma correlate with IL-2 administration. Semin Cancer Biol 2003; 13: 449-59.

35 Daud AI, DeConti RC, Andrews S et al. Phase I trial of interleukin-12 plasmid electroporation in patients with metastatic melanoma. J Clin Oncol 2008; 26: 5896903.

36 Testori A, Rossi CR, Tosti G. Utility of electrochemotherapy in melanoma treatment. Curr Opin Oncol 2012; 24: 155-61.

37 Larkin JO, Collins CG, Aarons S et al. Electrochemotherapy: aspects of preclinical development and early clinical experience. Ann Surg 2007; 245: 469-79.

38 Mali B, Miklavcic D, Campana LG et al. Tumor size and effectiveness of electrochemotherapy. Radiol Oncol 2013; 47: 32-41.

39 Calvet CY, Famin D, Andre FM et al. Electrochemotherapy with bleomycin induces hallmarks of immunogenic cell death in murine colon cancer cells. Oncoimmunology 2014; 3: e28131.

40 Bentzen SM. Preventing or reducing late side effects of radiation therapy: radiobiology meets molecular pathology. Nat Rev Cancer 2006; 6: 702-13.

41 Brush J, Lipnick SL, Phillips T et al. Molecular mechanisms of late normal tissue injury. Semin Radiat Oncol 2007; 17: 121-30.

42 Kranjc S, Tevz G, Kamensek U et al. Radiosensitizing effect of electrochemotherapy in a fractionated radiation regimen in radiosensitive murine sarcoma and radioresistant adenocarcinoma tumor model. Radiat Res 2009; 172: 677-85.

43 Raeisi E, Aghamiri SM, Bandi A et al. The antitumor efficiency of combined electrochemotherapy and single dose irradiation on a breast cancer tumor model. Radiol Oncol 2012; 46: 226-32.

44 Sersa G, Kranjc S, Cemazar M. Improvement of combined modality therapy with cisplatin and radiation using electroporation of tumors. Int J Radiat Oncol Biol Phys 2000; 46: 1037-41.

45 Todorovic V, Sersa G, Mlakar V et al. Metastatic potential of melanoma cells is not affected by electrochemotherapy. Melanoma Res 2011; 21: 196-205.

46 Gerlini G, Di Gennaro P, Borgognoni L. Enhancing anti-melanoma immunity by electrochemotherapy and in vivo dendritic-cell activation. Oncoimmunology 2012; 1: 1655-7.

47 Gerlini G, Sestini S, Di Gennaro P et al. Dendritic cells recruitment in melanoma metastasis treated by electrochemotherapy. Clin Exp Metastasis 2013; 30: 37-45. Quaglino P, Osella-Abate S, Marenco F et al. FoxP3 expression on melanoma cells is related to early visceral spreading in melanoma patients treated by

This article is protected by copyright. All rights reserved. 
electrochemotherapy. Pigment Cell Melanoma Res 2011; 24: 7

49 Mozzillo N, Simeone E, Benedetto L et al. Assessing a novel immuno-oncologybased combination therapy: Ipilimumab plus electrochemotherapy. Oncoimmunology 2015; 4: e1008842.

50 Valpione S, Martinoli C, Fava P et al. Personalised medicine: Development and external validation of a prognostic model for metastatic melanoma patients treated with ipilimumab. Eur J Cancer 2015; 51: 2086-94.

TABLE 1 Patients characteristics

\begin{tabular}{|c|c|c|c|c|}
\hline & \multicolumn{2}{|c|}{$\begin{array}{l}\text { Treated patients } \\
\qquad(\mathrm{n}=151)\end{array}$} & \multicolumn{2}{|c|}{$\begin{array}{l}\text { Evaluable patients } \\
\qquad(\mathrm{n}=114)\end{array}$} \\
\hline Age (median [I.Q. range]) & 75 & $65-82$ & 76 & $70-82$ \\
\hline age & $\begin{array}{c}151 \\
\text { patients }\end{array}$ & $\%$ & 114 patients & $\%$ \\
\hline$<50$ & 11 & $7 \%$ & 4 & $4 \%$ \\
\hline $50-59$ & 7 & $5 \%$ & 3 & $3 \%$ \\
\hline $60-69$ & 29 & $19 \%$ & 21 & $18 \%$ \\
\hline $70-79$ & 46 & $31 \%$ & 40 & $35 \%$ \\
\hline $80+$ & 58 & $38 \%$ & 46 & $40 \%$ \\
\hline $\begin{array}{l}\text { Years since diagnosis (median [I.Q. } \\
\text { range]) }\end{array}$ & 2 & $1-5$ & 2 & $1-4$ \\
\hline SEX (M:F) & 59:92 & $39 \%: 61 \%$ & $42: 72$ & $37 \%: 63 \%$ \\
\hline \multicolumn{5}{|l|}{ TNM AT DIAGNOSIS } \\
\hline $\mathrm{T}(\mathrm{T} 1, \mathrm{~T} 2, \mathrm{~T} 3, \mathrm{~T} 4, \mathrm{Tx}, \mathrm{Tis})$ & \multicolumn{2}{|c|}{$11,31,42,30,16,21$} & \multicolumn{2}{|c|}{$9,24,33,21,13,14$} \\
\hline $\mathrm{N}(\mathrm{N} 0, \mathrm{~N} 1, \mathrm{~N} 2, \mathrm{~N} 3, \mathrm{Nx})$ & \multicolumn{2}{|c|}{$92,16,18,16,9$} & \multicolumn{2}{|c|}{$71,13,14,9,7$} \\
\hline $\mathrm{M}(\mathrm{M} 0, \mathrm{M} 1, \mathrm{Mx})$ & \multicolumn{2}{|c|}{$125,19,7$} & \multicolumn{2}{|c|}{$98,9,7$} \\
\hline \multicolumn{5}{|l|}{ PREVIOUS TREATMENTS } \\
\hline Surgery & 105 & $70 \%$ & 76 & $67 \%$ \\
\hline Chemotherapy & 44 & $29 \%$ & 28 & $25 \%$ \\
\hline Radiotherapy & 29 & $19 \%$ & 17 & $15 \%$ \\
\hline Isolated limb perfusion & 8 & $5 \%$ & 7 & $6 \%$ \\
\hline Other & 85 & $56 \%$ & 60 & $53 \%$ \\
\hline \multicolumn{5}{|l|}{ \# ECT PER PATIENT } \\
\hline 1 & 123 & $82 \%$ & 87 & $76 \%$ \\
\hline 2 & 21 & $14 \%$ & 20 & $18 \%$ \\
\hline 3 & 5 & $3 \%$ & 5 & $4 \%$ \\
\hline 4 & 2 & $1 \%$ & 2 & $2 \%$ \\
\hline \multicolumn{5}{|l|}{ LESIONS } \\
\hline Total number of skin lesions & \multicolumn{2}{|c|}{506} & \multicolumn{2}{|c|}{394} \\
\hline $\begin{array}{l}\text { Lesions per patient (median [I.Q. } \\
\text { range]) }\end{array}$ & 3 & $1-6$ & 3 & $1-6$ \\
\hline SIZE (median [I.Q. range]) & 10 & $5-20$ & 9 & $5-20$ \\
\hline$<5 \mathrm{~mm}$ & 182 & $36 \%$ & 144 & $36 \%$ \\
\hline $6-10 \mathrm{~mm}$ & 128 & $25 \%$ & 109 & $28 \%$ \\
\hline $11-20 \mathrm{~mm}$ & 80 & $16 \%$ & 58 & $15 \%$ \\
\hline $21-30 \mathrm{~mm}$ & 44 & $9 \%$ & 32 & $8 \%$ \\
\hline
\end{tabular}

This article is protected by copyright. All rights reserved. 


\begin{tabular}{|l|c|c|c|c|}
\hline$>30$ mm & 72 & $14 \%$ & 51 & $13 \%$ \\
\hline $\begin{array}{l}\text { LOCALISATION LARGEST } \\
\text { NODULE }\end{array}$ & & & & \\
\hline Head/Neck & 15 & $10 \%$ & 11 & $10 \%$ \\
\hline Trunk & 24 & $16 \%$ & 13 & $11 \%$ \\
\hline Limbs & 104 & $69 \%$ & 84 & $74 \%$ \\
\hline Multiple sites & 8 & $5 \%$ & 6 & $5 \%$ \\
\hline CURRENT PER NODULE & & & & \\
\hline$<1.5 \mathrm{~A}$ & 73 & $15 \%$ & 58 & $15 \%$ \\
\hline $1.6-3 \mathrm{~A}$ & 178 & $35 \%$ & 140 & $35 \%$ \\
\hline $3.1-5 \mathrm{~A}$ & 127 & $25 \%$ & 101 & $26 \%$ \\
\hline $5.1-7 \mathrm{~A}$ & 75 & $15 \%$ & 59 & $15 \%$ \\
\hline $7.1-10 \mathrm{~A}$ & 41 & $8 \%$ & 28 & $7 \%$ \\
\hline$>10 \mathrm{~A}$ & 12 & $2 \%$ & 8 & $2 \%$ \\
\hline & & & & \\
\hline Plate ELECTRODES & 20 & $4 \%$ & 13 & $3 \%$ \\
\hline Row needle & 67 & $13 \%$ & 57 & $15 \%$ \\
\hline Hexagonal & 383 & $76 \%$ & 304 & $77 \%$ \\
\hline Multiple electrodes & 36 & $7 \%$ & 20 & $5 \%$ \\
\hline Preirradiated area (YES:NO) & $37: 469$ & $7 \%: 93 \%$ & $19: 375$ & $5 \%: 95 \%$ \\
\hline Deep margins reached (YES:NO) & $363: 143$ & $72 \%: 28 \%$ & $283: 111$ & $72 \%: 28 \%$ \\
\hline Lateral margins reached (YES:NO) & $385: 121$ & $76 \%: 24 \%$ & $295: 99$ & $75 \%: 25 \%$ \\
\hline
\end{tabular}

Table 2 Pain evaluation by Numeric Rating Scale (NRS)

\begin{tabular}{|l|c|c|c|l|}
\hline & $\begin{array}{c}\text { Before } \\
\text { ECT }\end{array}$ & $\begin{array}{c}\text { Within } \\
\mathbf{6 0} \\
\text { days }\end{array}$ & $\begin{array}{c}\text { After } \\
60 \\
\text { days }\end{array}$ & P value \\
\hline Pain NRS & & & & \\
\hline Median NRS & 0 & 1 & 1 & \\
\hline NRS range (min-max) & $0-8$ & $0-10$ & $0-8$ & \\
\hline & & & & \\
\hline Pain NRS categories & & & & \\
\hline 0-2 Mild pain & $77 \%$ & $70 \%$ & $68 \%$ & \\
\hline 3-5 Moderate pain & $16 \%$ & $19 \%$ & $20 \%$ & \\
\hline 6-10 Severe pain & $7 \%$ & $11 \%$ & $12 \%$ & \\
\hline & & & & $\mathrm{P}=0.5892$ \\
\hline & & & & \\
\hline Pain medication & & & & \\
\hline No pain & $50 \%$ & $41 \%$ & $47 \%$ & \\
\hline Pain sometimes, controlled by non-opioids & $31 \%$ & $24 \%$ & $21 \%$ & \\
\hline Pain controlled by non-opioids & $15 \%$ & $21 \%$ & $25 \%$ & \\
\hline Pain controlled by opioids & $1 \%$ & $4 \%$ & $0 \%$ & \\
\hline Uncontrolled pain & $1 \%$ & $4 \%$ & $8 \%$ & \\
\hline & & & & $\mathrm{P}=0.0561$ \\
\hline
\end{tabular}

Numeric Rating Scale (NRS)

$p$ values of Chi square for trend

This article is protected by copyright. All rights reserved. 
TABLE 3. Response to ECT correlated to tumour size

\begin{tabular}{|l|c|c|c|c|c|c|c|c|c|c|}
\hline SIZE & $<\mathbf{5 ~} \mathbf{~ m m}$ & $\%$ & $\mathbf{6 - 1 0} \mathbf{~ m m}$ & $\%$ & $\mathbf{1 1 - 2 0} \mathbf{~ m m}$ & $\%$ & $\mathbf{2 1 - 3 0} \mathbf{~ m m}$ & $\%$ & $>\mathbf{3 0} \mathbf{~ m m}$ & $\%$ \\
\hline CR & 94 & $68 \%$ & 70 & $64 \%$ & 32 & $56 \%$ & 11 & $34 \%$ & 19 & $38 \%$ \\
\hline NOT CR & 45 & $32 \%$ & 39 & $36 \%$ & 25 & $44 \%$ & 21 & $66 \%$ & 31 & $62 \%$ \\
\hline
\end{tabular}

Chi square for trend $=20.385$ ( 1 degree of freedom) P VALUE $<0.0001$

\begin{tabular}{|l|c|c|c|c|c|c|c|c|c|c|}
\hline & & & & & & & & & & \\
\hline OR & 110 & $79 \%$ & 86 & $79 \%$ & 42 & $74 \%$ & 25 & $78 \%$ & 38 & $76 \%$ \\
\hline NOT OR & 29 & $21 \%$ & 23 & $21 \%$ & 15 & $26 \%$ & 7 & $22 \%$ & 12 & $24 \%$ \\
\hline
\end{tabular}

Chi square for trend $=0.3527$ ( 1 degree of freedom) P VALUE $=0.5526$

Complete response $(\mathrm{CR})$ disappearance of the target lesion

Overall response $(\mathrm{OR})$ is $\mathrm{CR}+\mathrm{Partial}$ response $(\mathrm{PR})$ at least $30 \%$ decrease in the diameter of the target lesion

TABLE 4. Significant factors associated with response to ECT related to nodules

\begin{tabular}{|c|c|c|c|c|}
\hline VARIABLES & \multicolumn{2}{|c|}{$\% \mathrm{CR}$} & ODDS RATIO & $\mathrm{P}$ value \\
\hline Lesion size $(\mathrm{mm})$ & $\begin{array}{l}\leq 30 \\
>30\end{array}$ & $\begin{array}{l}62.9 \% \\
35.3 \%\end{array}$ & $1.76(1.34-2.32)$ & 0.00005 \\
\hline Visceral mts & $\begin{array}{l}\text { YES } \\
\text { NO }\end{array}$ & $\begin{array}{l}30.0 \% \\
49.5 \%\end{array}$ & $0.59(0.45-0.77)$ & 0.0001 \\
\hline Lymphoedema & $\begin{array}{l}\text { YES } \\
\text { NO }\end{array}$ & $\begin{array}{l}62.0 \% \\
61.7 \%\end{array}$ & $1.01(0.78-1.31)$ & 0.9535 \\
\hline Pre-irradiated area & $\begin{array}{l}\text { YES } \\
\text { NO }\end{array}$ & $\begin{array}{l}31.6 \% \\
59.5 \%\end{array}$ & $0.56(0.34-0.92)$ & 0.0219 \\
\hline Deep margins treated & $\begin{array}{l}\text { YES } \\
\text { NO }\end{array}$ & $\begin{array}{l}64.7 \% \\
41.4 \% \\
\end{array}$ & $1.61(1.28-2.01)$ & 0.00003 \\
\hline Lateral margins treated & $\begin{array}{l}\text { YES } \\
\text { NO }\end{array}$ & $\begin{array}{l}62.7 \% \\
44.4 \% \\
\end{array}$ & $1.45(1.15-1.83)$ & 0.0016 \\
\hline , & & $\overline{\mathrm{OR}}$ & $\begin{array}{c}\text { ODDS RATIO } \\
\text { (C.I. 95\%) }\end{array}$ & $P$ value \\
\hline Lesion size $(\mathrm{mm})$ & $\begin{array}{l}\leq 30 \\
>30\end{array}$ & $\begin{array}{l}77.5 \% \\
76.5 \%\end{array}$ & $1.02(0.74-1.39)$ & 0.9364 \\
\hline Visceral mts & $\begin{array}{l}\text { YES } \\
\text { NO }\end{array}$ & $\begin{array}{l}75.0 \% \\
72.5 \%\end{array}$ & $1.11(0.80-1.54)$ & 0.5408 \\
\hline Lymphoedema & $\begin{array}{l}\text { YES } \\
\text { NO }\end{array}$ & $\begin{array}{l}96.2 \% \\
75.9 \%\end{array}$ & $2.84(1.56-5.14)$ & 0.0006 \\
\hline Pre-irradiated area & $\begin{array}{l}\text { YES } \\
\text { NO }\end{array}$ & $\begin{array}{l}63.2 \% \\
78.4 \%\end{array}$ & $1.48(0.92-2.40)$ & 0.1096 \\
\hline Deep margins treated & $\begin{array}{l}\text { YES } \\
\text { NO }\end{array}$ & $\begin{array}{l}85.2 \% \\
58.5 \%\end{array}$ & $2.09(1.62-2.69)$ & $<0.00001$ \\
\hline Lateral margins treated & $\begin{array}{l}\text { YES } \\
\text { NO }\end{array}$ & $\begin{array}{l}83.0 \% \\
61.6 \%\end{array}$ & $1.80(1.40-2.33)$ & 0.00001 \\
\hline
\end{tabular}

Complete response (CR) disappearance of the target lesion

Overall response (OR) is CR + Partial response (PR) at least $30 \%$ decrease in the diameter of the target lesion

This article is protected by copyright. All rights reserved. 
TABLE 5. LOGISTIC MULTIVARIATE ANALYSIS. Response to ECT related to nodules.

\begin{tabular}{|c|c|c|c|c|}
\hline \multicolumn{5}{|c|}{ LOGISTIC MULTIVARIATE ANALYSIS FOR COMPLETE RESPONSE } \\
\hline & COEFF. & ST.ERR. & $\begin{array}{c}\text { ODDS RATIO (C.I. } \\
\text { 95\%) }\end{array}$ & $\begin{array}{c}\text { P } \\
\text { VALUE }\end{array}$ \\
\hline LESION SIZE $\leq 3 \mathrm{CM}$ & 1.31 & 0.33 & $3.69(1.95-6.98)$ & $<0.0001$ \\
\hline $\begin{array}{lll}\text { ABSENCE } & \text { OF } & \text { VISCERAL } \\
\text { METASTASES } & & \\
\end{array}$ & -0.08 & 0.37 & $0.92(0.44-1.91)$ & 0.829 \\
\hline PRESENCE OF LYMPHOEDEMA & -0.37 & 0.30 & $0.69(0.38-1.24)$ & 0.215 \\
\hline NOT PREIRRADIATED AREA & 1.17 & 0.58 & $3.24(1.04-10.09)$ & 0.043 \\
\hline DEEP MARGINS TREATED & 2.40 & 0.69 & $10.98(2.85-42.29)$ & 0.0005 \\
\hline LATERAL MARGINS TREATED & -1.01 & 0.70 & $0.36(0.09-1.43)$ & 0.147 \\
\hline \multicolumn{5}{|c|}{ LOGISTIC MULTIVARIATE ANALYSIS FOR OBJECTIVE RESPONSE } \\
\hline & COEFF. & ST.ERR. & $\begin{array}{c}\text { ODDS RATIO (C.I. } \\
\text { 95\%) }\end{array}$ & $\begin{array}{c}\text { P } \\
\text { VALUE }\end{array}$ \\
\hline LESION SIZE $\leq 3 \mathrm{CM}$ & -0.50 & 0.48 & $0.61(0.24-1.55)$ & 0.296 \\
\hline $\begin{array}{l}\text { ABSENCE } \\
\text { METASTASES }\end{array}$ & 3.31 & 1.13 & $27.50(3.01-251.21)$ & 0.0033 \\
\hline PRESENCE OF LYMPHOEDEMA & 1.45 & 0.64 & $4.28(1.23-14$ & 0.022 \\
\hline NOT PREIRRADIATED AREA & 1.58 & 0.73 & $4.28(1.15-20.31)$ & 0.032 \\
\hline DEEP MARGINS TREATED & 3.35 & 0.73 & $28.45(6.78-119.32)$ & $<0.0001$ \\
\hline LATERAL MARGINS TREATED & -1.37 & 0.72 & $0.25(0.06-1.04)$ & 0.056 \\
\hline
\end{tabular}

This article is protected by copyright. All rights reserved. 
Figure 1. Local tumour control curve

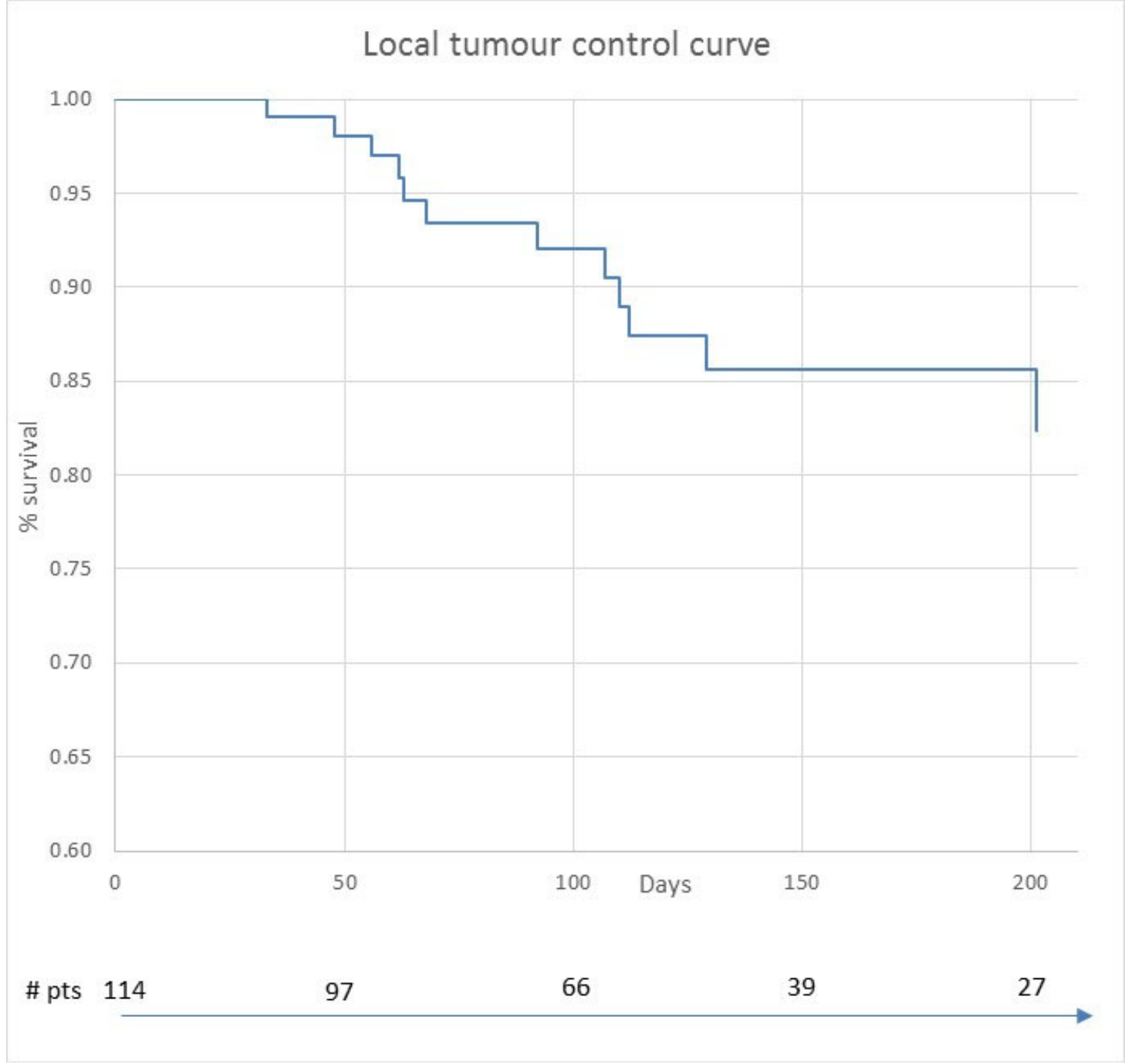

This article is protected by copyright. All rights reserved. 

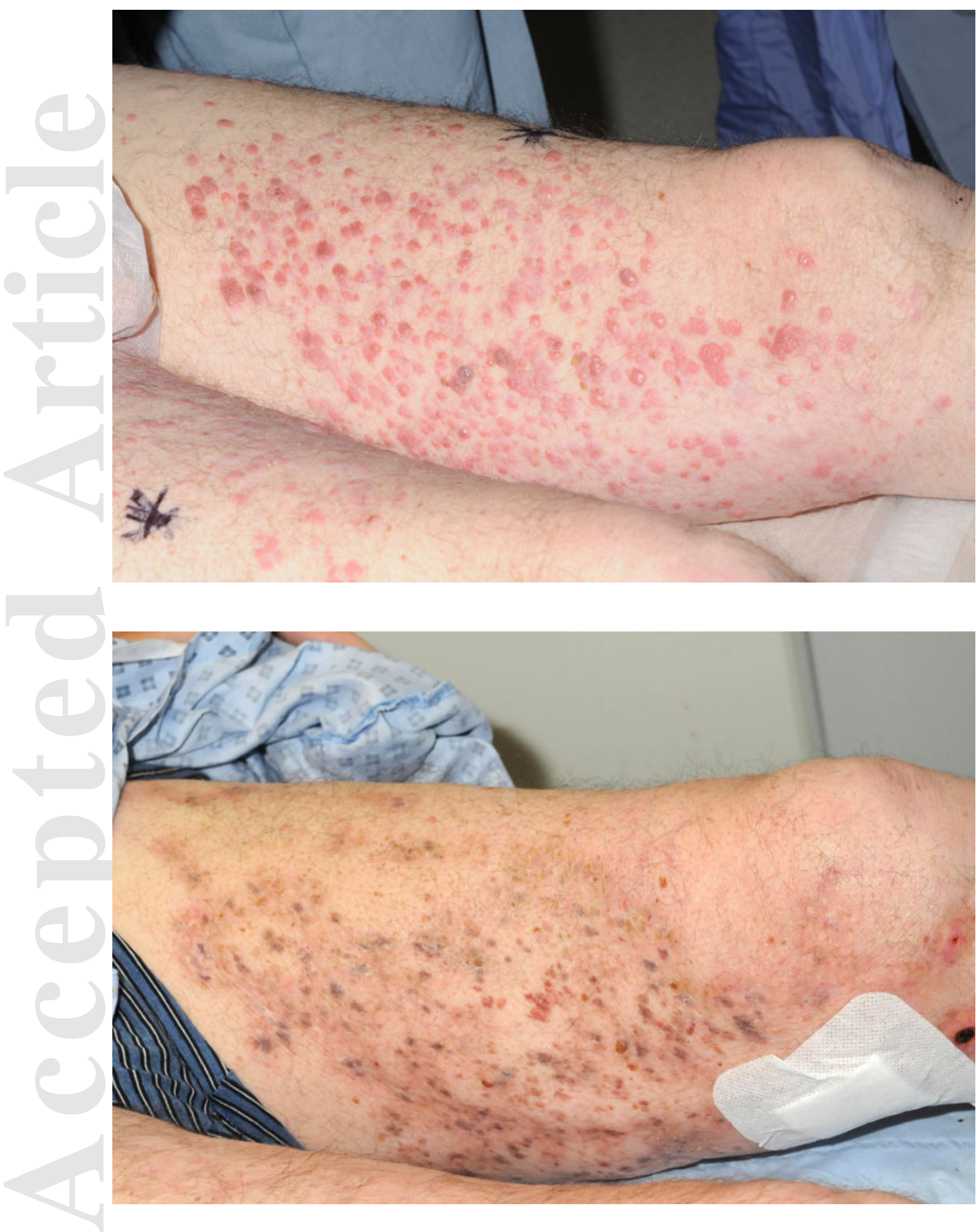

This article is protected by copyright. All rights reserved. 